\title{
Genomic fingerprinting of penicillinase-producing strains of Neisseria gonorrhoeae in Valencia, Spain
}

\author{
M A Dasi, J M Nogueira, J J Camarena, C Gil, R García-Verdú, J L Barberá, J Barberá
}

\begin{abstract}
Objective-To compare the value of different markers and their combinations with the restriction enzyme technique in the differentiations of penicillinase-producing $\boldsymbol{N}$. gonorrhoeae (PPNG) strains. Materials and methods-17 PPGN strains isolated from symptomatic, untreated male patients with urethritis were characterised by antibiotic sensitivity testing, auxotyping, serotyping, plasmid profile, and restriction endonuclease fingerprinting (Hind III digestion). Cluster analysis with the method of unweighted pair-group average (UPGMA) linkage was used to calculate similarity or dissimilarity for PPNG strains.

Main Results-Either auxotyping or plasmid profile alone differentiated three groups of PPNG strains, whereas the combination auxotyping/serotyping identified 10. Although the combination auxotying/serotyping/plasmid profile and the restriction enzyme technique showed a similar discrimination ability (differentiation of 11 PPNG strains), genomic fingerprinting gave highly specific restriction patterns on individual gonoccocal isolates.

Conclusions-The combination of different markers gave more epidemiological information than the use of only one. The sequence of discriminating ability for PPNG strains was: auxotyping/serotyping < auxotyping/serotyping/plasmid profile < restriction patterns of genomic DNA.
\end{abstract}

\section{Introduction}

The incidence of penicillinase (beta-lactamase)-producing strains of Neisseria gonorrhoeae has been steadily increasing in most European countries, including Spain. ${ }^{1}$ Phenotypic and genotypic characterisation of these strains has proved valuable for epidemiological tracing in gonococcal disease. Auxotyping, ${ }^{2}$ antibiotic susceptibility testing, ${ }^{3}$ serogrouping, 4-9 $^{-9}$ plasmid analysis, and the so-called genomic fingerprinting based on restriction endonuclease digestion of the gonococcal DNA, ${ }^{10}{ }^{11}$ have been used by different research groups as epidemiological tools for differentiating between penicillinase-producing $N$. gonorrhoeae strains. Genomic fingerprinting gives highly reproducible, stable, and specific restriction patterns on individual gonococcal isolates $^{12-16}$ and can serve as a useful adjunct to serological classification.
We compared the value of different markers and their combinations with the restriction enzyme technique in the differentiation of penicillinase-producing strains of $N$. gonorrhoeae.

\section{Materials and methods}

Gonococcal strains

A total of 17 penicillase-producing $N$. gonorrhoeae strains isolated from symptomatic, untreated male patients with urethritis in Valencia, Spain, between 1985 and 1988 were included in the study. They accounted for $9.9 \%$ of all isolates of $N$. gonorrhoeae during this period.

All isolates were confirmed as $N$. gonorrhoeae by colony morphology, Gram stain, oxidase reaction, and acid reproduction from glucose but not maltose, sucrose, lactose or fructose. Purified stock cultures were maintained in trypticase-soy broth (BBL Microbiology Systems, Cockeysville, MD, USA) containing $20 \%$ glycerol and stored at $-70^{\circ} \mathrm{C}$. Isolates were subcultured on GC agar medium base (Oxoid, UK) with $1 \%$ (v/v) haemoglobin (BBL), 1\% (v/v) IsoVitalex (BBL) and without antibiotics, and incubated at $37^{\circ} \mathrm{C}$ with $5 \%$ $\mathrm{CO}_{2}$ atmosphere in a humidified incubator for $20 \mathrm{~h}$. The strain number was that assigned in our laboratory.

The isolates were tested for $\beta$-lactamase production by means of the chromogenic cephalosporin test. ${ }^{17}$

\section{Antibiotic sensitivity testing}

We tested sensitivity to antibiotic by an agar dilution method ${ }^{3}$ using GC agar base enriched with $1 \%(\mathrm{v} / \mathrm{v})$ IsoVitalex containing various concentrations $(0.125$ to $128 \mathrm{mg} / \mathrm{l})$ of penicillin G; $10^{4}$ colony forming units (cfu) were transferred to the agar surface. The minimum inhibitory concentration (MIC) was defined as the lowest concentration that completely suppressed bacterial growth after 18-24 h incubation.

\section{Auxotyping}

Auxotyping was performed by growing $N$. gonorrhoeae on chemically defined medium as described previously. ${ }^{2}$ Strains were tested for their requirements for proline (Pro ${ }^{-}$), arginine ( $\left.\mathrm{Arg}^{-}\right)$, methionine (Met ${ }^{-}$), hypoxanthine $\left(\mathrm{Hyx}^{-}\right)$, and uracil $\left(\mathrm{Ura}^{-}\right)$or combinations of these requirements. Strains with no special requirements regarding these substances were called prototrophic (Proto). 
Table Distribution of 17 penicillinase-producing Neisseria gonorrhoeae strains regarding minimum inhibitory concentrations (MIC), plasmid size, auxotype, and serogroup and serivar patterns.

\begin{tabular}{|c|c|c|c|c|}
\hline $\begin{array}{l}\text { Strain } \\
\text { designation }\end{array}$ & $\begin{array}{l}M I C \\
(m g / l)\end{array}$ & $\begin{array}{l}\text { Plasmid size } \\
\text { (megadaltons) }\end{array}$ & Auxotype & Serogroup/serovar \\
\hline $\begin{array}{r}20 \\
44 \\
52 \\
64 \\
76 \\
93 \\
96 \\
99 \\
102 \\
103 \\
115 \\
136 \\
167 \\
171 \\
180 \\
185 \\
186\end{array}$ & $\begin{array}{r}32 \\
64 \\
>128 \\
64 \\
16 \\
64 \\
>128 \\
16 \\
>128 \\
128 \\
>128 \\
64 \\
128 \\
8 \\
128 \\
128 \\
>128\end{array}$ & $\begin{array}{l}3 \cdot 2 \\
4 \cdot 5 \\
4 \cdot 5 \\
3 \cdot 2 \\
3 \cdot 2 \\
4 \cdot 5 \text { and } 24 \cdot 5 \\
3 \cdot 2 \\
3 \cdot 2 \\
3 \cdot 2 \\
3 \cdot 2 \\
3 \cdot 2 \\
4 \cdot 5 \\
3 \cdot 2 \\
3 \cdot 2 \\
4 \cdot 5 \\
3 \cdot 2 \\
3 \cdot 2\end{array}$ & $\begin{array}{l}\text { Arg } \\
\text { Proto } \\
\text { Proto } \\
\text { Proto } \\
\text { Proto } \\
\text { Pro } \\
\text { Pro } \\
\text { Proto } \\
\text { Pro- } \\
\text { Pro } \\
\text { Pro } \\
\text { Proto } \\
\text { Pro } \\
\text { Proto } \\
\text { Proto } \\
\text { Pro } \\
\text { Proto }\end{array}$ & $\begin{array}{l}\text { IA/rst } \\
\text { IB/rop } \\
\text { IB/rop } \\
\text { IB/x } \\
\text { IB/o } \\
\text { IB/rop } \\
\text { IB/pyvut } \\
\text { IB/x } \\
\text { IB/opt } \\
\text { IB/pu } \\
\text { IB/pyvut } \\
\text { IB/rop } \\
\text { IB/pyvut } \\
\text { IB/rop } \\
\text { IB/rop } \\
\text { IB/pyvut } \\
\text { IA/v }\end{array}$ \\
\hline
\end{tabular}

\section{Plasmid analysis}

Plasmids were isolated by a rapid alkaline extraction procedure as described by Birnboim and Doly, ${ }^{18}$ with some modifications. ${ }^{19}$ Plasmids were analysed in $0.8 \%$ agarose gels. The Escherichia coli V517 strain $^{20}$ (size estimates of plasmids $1 \cdot 8,2 \cdot 0,2 \cdot 6,3 \cdot 4,3 \cdot 7,4 \cdot 8$ and $35 \cdot 8$ $10^{6}$ daltons) and $N$. gonorrhoeae strains CCUG 5449 (size estimates of plasmids $3 \cdot 2$ and $2 \cdot 6$ $10^{6}$ daltons) and CCUG 6016 (size estimates of plasmids $24.5,4.5$ and $2.610^{\circ}$ daltons) (Cuture collection, University of Göteborg, Sweden) with plasmids of known molecular weight were included as fragment size markers.

\section{Serological classification}

Serological classification into serogroups (WI, WII, and WIII) and serovars was performed by co-agglutination as described previously ${ }^{421}$ using a set of monocolonal antibodies bound to staphylococci containing protein A (provided by $S$ Bygdeman, Huddings University

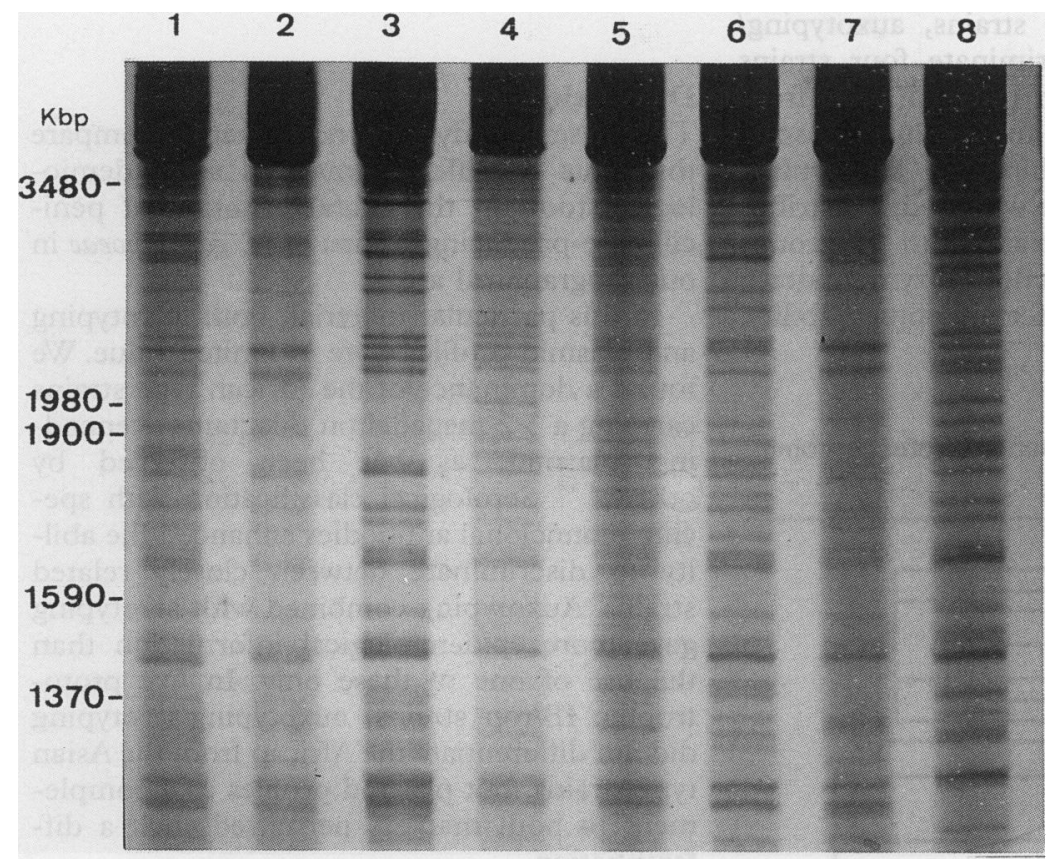

Fig 1 Genetic heterogeneity of $\mathrm{N}$. gonorrhoeae strains after DNA digestion with Hind III (lane numbers $1-8$ corresponding to strains 52,171,102,93,185,20,186, and 103). bp, base pairs.
Hospital, Stockholm, Sweden). Each strain was tested against a set of five antibodies specific to protein $\mathrm{AI}$ (designated Ar, Ao, As, At, and $A v)$ and nine antibodies specific to protein $\mathrm{IB}(\mathrm{Br}, \mathrm{Bo}, \mathrm{Bp}, \mathrm{By}, \mathrm{Bv}, \mathrm{Bu}, \mathrm{Bs}, \mathrm{Bt}$, and Bx).

Penicillinase-producing strains of $N$. gonorrhoeae were distributed into serovars according to their reactions with the different monoclonal antibody reagents. The capital letters $A$ (for WI strains) and B (for WII/WIIII) were followed by lower case letters representing positive reactions with the corresponding coagglutination reagents.

\section{Restriction endonuclease fingerprinting}

The restriction enzyme technique was performed as described by Falk et al ${ }^{10}$ with some modifications. The restriction endonuclease used was Hind III (Boehringer GmbH, Mannheim, Germany). After electrophoresis, gels were stained with silver (Bio-Rad Lab., Richmond, CA, USA) or alternatively with ethidium bromide. Electrophoretograms were scanned with an LKB2202 UltroScan laser densitometer (Pharmacia LKB, Uppsala, Sweden) provided with a Hewlett-Packard 3390 integrator. The molecular weight of each digested DNA fragment was calculated by a computer program of robust estimation described by Plikaitis et al. $^{22}$

\section{Statistical methods}

Statistical analyses of data for grouping different isolates were carried out by assigning to each electrophoretogram a dimensional vector " $n$ " of presence/absence (presence $=1$, absence $=0$ ), where " $n$ " was the total number of resulting DNA fragments. These vectors were introduced into a program of cluster analysis using the "proximities" procedure ${ }^{23}$ for estimating the distance matrix (SM) according to the following equation: $\operatorname{SM}(x, y)$ $=a+d / a+b+c+d$, where SM $(x, y)$ was the similarity coefficient between two strains; " $a$ " the number of DNA fragments which were present in both strains; " $b$ " the number of DNA fragments which were present in the " $x$ " strain and absent in the " $y$ " strain; "c" the number of DNA fragments which were present in the " $y$ " strain and absent in the " $x$ " strain; and " $d$ " the number of DNA fragments which were absent in both strains. Once this matrix has been calculated, the cluster analysis with the method of unweighted pair-group average (UPGMA) linkage was used. In order to obtain a graphic representation (dendrogram), the program used converted the similarity coefficients [SM ( $x, y)]$ into $\mathrm{RD}(\mathrm{x}, \mathrm{y})$ (rescaled distance cluster combine) according to the following formula:

$$
R D(x, y)=\frac{1-S M(x, y)}{S M m a x-S M \min } \times N
$$

where, "Smax" and "Smin" were the values of the maximum and minimum similarity coefficients and " $N$ " the index of the scale. Analyses were carried out with SPSS $^{24}$ running on a Honeywell Bull computer. 


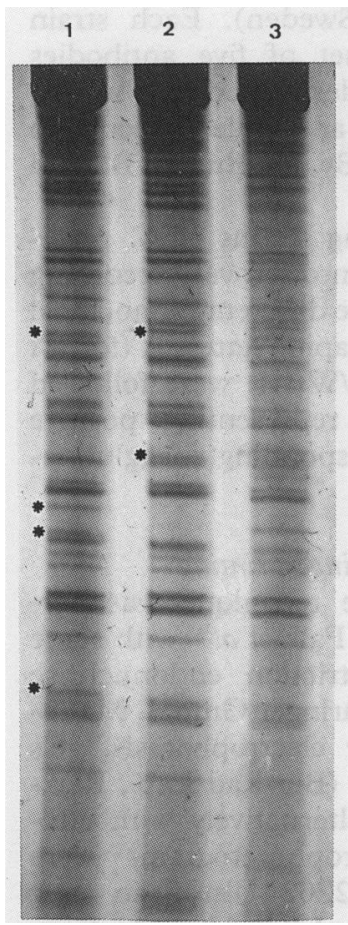

Fig 2 The restriction enzyme patterns of strains 99 and 64 lanes 1 and 2 , respectively) with identical plasmid size, auxotype and serovar patterns differed only with regard to 2 or 4 bands; * presencelabsence of bands (silver stain).
Fig 3 Dendogram of penicillinase-producing $\mathrm{N}$. gonorrhoeae strains. Clusters of strains ( $a, b, c$ j) at the 8 cutoff level.
Results

All isolates were $\beta$-lactamase producers with MIC values of penicillin ranging between 8 and $>128 \mathrm{mg} / \mathrm{l}$ (table). Three different auxotypes were identified. Nine of the 17 strains were Proto, seven were Pro ${ }^{-}$, and only one was $\mathrm{Arg}^{-}$(table).

The $3 \cdot 2$ megadalton or Africa $\left(\mathrm{Af}^{-}\right.$) plasmid was found in $12(70.6 \%)$ strains. Four strains contained the 4.5 megadalton or Asia $\left(\mathrm{As}^{-}\right.$) plasmid. In one strain the conjugative 24.5 megadalton plasmid coexisted with the 4.5 megadalton plasmid $\left(\mathrm{As}^{+}\right)$. The cryptic $2 \cdot 6$ megadalton plasmid was present in all 17 strains (table).

Serogroup WI was represented by two isolates which belonged to the serovars Arst and Av. Serogroup WII/WIII was represented by 15 strains belonging to six different serovars (table). The serovar pattern Brop was identified in $35 \%$ of the isolates.

Restriction patterns obtained with Hind III digestion of genomic DNA of different isolates consisted of a mean of 50 bands per pattern of which size of fragments between 2.4 and 1.3 kilobase pairs (containing a median of 25 to 30 bands) were studied (fig 1). Three common bands with fragment sizes of $2 \cdot 1,1 \cdot 5$, and $1 \cdot 3$ kilobase pairs, respectively, were found in all lanes. Highly resolved bands standing out minimal differences between two isolates were obtained with silver stain (fig 2).

Statistical grouping of isolates showed similarity coefficients between 1.0 and 0.7456 [RD (x, y) 0 and 17 , respectively]. With a cutoff level at rescaled distance cluster [RD $(x, y)]$ of 8 , four clearly defined clusters of $N$. gonorrhoeae strains were identified. Figure 3 shows the grouping dendrogram.

Discrimination by different markers and their combinations is shown in fig 4. Auxotyping differentiated three groups of strains of $N$. gonorrhoeae, whereas the combination auxotyping/serotyping differentiated 10. Among the five prototrophic IB/rop strains, auxotyping/ serotyping did not discriminate four strains with the 4.5 megadalton plasmid( $\mathrm{As}^{-}$) from one strain with the 3.2 megadalton plasmid (Af ${ }^{-}$). When the combination auxotyping/ serotyping/plasmid profile was used, a distribution of $N$. gonorrhoeae strains into 11 groups was obtained. The restriction enzyme pattern showed a similar discrimination ability,

Rescaled distance cluster combine

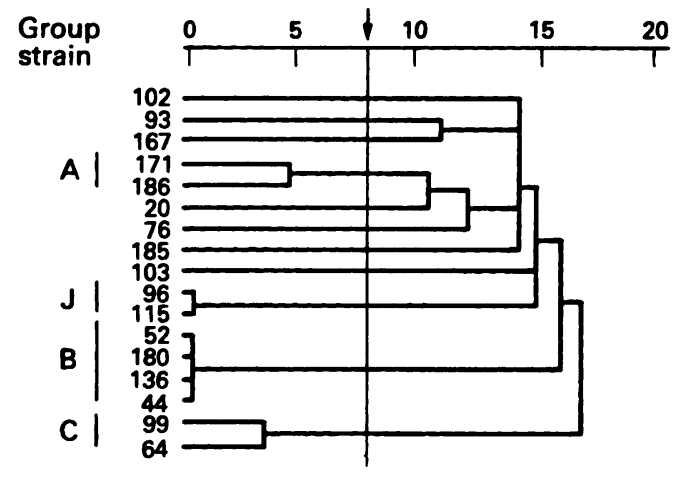

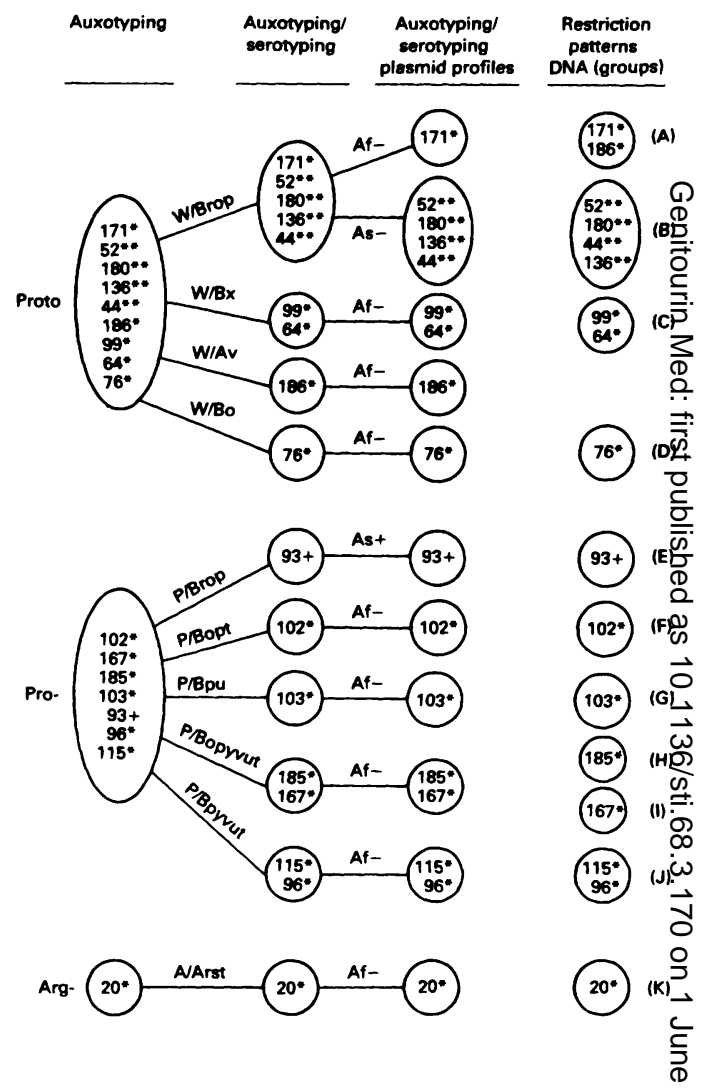

Fig 4 Phenotypic and genotypic discrimination of 17 penicillinase-producing $\mathrm{N}$. gonorrhoeae strains. Auxotypes: Proto (prototrophic), Pro (proline), Arg (arginine). Plasmid profile and groups obtained with DNA restriction patterns, $\star 3 \cdot 2$ megadalton plasmid $(A f), \star * 4.5$ megadalton plasmid $\left(A s^{-}\right),+24.5$ and 4.5 megadalton plasmid $\left(\mathrm{As}^{+}\right)$

although it detected differences between two $\mathrm{Af}^{-}$strains (isolates 185 and 167) which were completely identical by combining the other markers. However, the restriction enzyme pate tern was unable to differentiate isolates $17 \bar{\Phi}$ and 186 (fig 4).

\section{Discussion}

The present study was undertaken to compare the value of different markers as epidemio․ logical tools in the characterisation of penf cillinase-producing strains of $N$. gonorrhoeae ip our geographical area.

In this particular material, both auxotyping and plasmid profiles were of limited value. WE found a dominance of the African type strains carrying a 3.2 megadalton $\beta$-lactamase encode ing plasmid, as has been observed by others. ${ }^{14}$ Serological classification with speo cific monoclonal antibodies enhanced the abif ity to discriminate between closely relateg strains. Auxotyping combined with serotypin gave more epidemiological information than the use of one of these only. In five prote trophic IB/rop strains, auxotyping/serotyping did not differentiate the African from the Asian type strains, but plasmid profiles as a complement to both markers permitted such a differentiation.

The distribution of gonococcal strains into 11 groups obtained with the combination of 
three markers (auxotyping/serotyping/plasmid profiles) was in agreement with the genomic fingerprinting. The restriction enzyme technique may differentiate between strains that by phenotypic classification appear to be identical. The reproducibility and reliability of the method has been demonstrated by other investigators. ${ }^{13-1625}$ Moreover, the use of silver stain has been proved a valuable alternative to ethidium bromide.

The characterisation of a clone as $\mathrm{As}^{+} \mathrm{IB} / \mathrm{rop}$ strains may have been linked to an outbreak that occurred in our urban area at the end of 1987. The two $\mathrm{Af}^{-} \mathrm{IB} / \mathrm{x}$ strains in which all markers and their combinations coincided, were similar to those described in an outbreak of penicillinase-producing strains of $N$. gonorrhoeae in the city of Barcelona (close to Valencia) in $1987 .{ }^{26}$

The combination of different markers has been shown to give more epidemiological information than the use of only one. Although the restriction enzyme technique appears to be highly specific, it is both laborious and expensive and usually limited to special laboratories. We conclude that the combination of serological classification with specific monoclonal antibodies with auxotyping and/or plasmid profiles is of great potential use for epidemiological and clinical studies. Genotypic fingerprinting could be of practical importance for detecting subtle genetic differences of phenotypically similar gonococcal clones.

This work was supported in part by "Fondo de Investigaciones Santarias de la Seguridad Social" (FIss) grant 90/0613. We thank Marta Pulido, M.D. for editorial assistance and copy editing.

1 Vásquez J, Fenoll A, Berrón S, Téllez A, Bilbao $R$ Penicillinase producing strains of Neisseria gonorrhoeae in Madrid. Genitourin Med 1985;61:139.

2 Catlin BW. Nutritional profiles of Neisseria gonorrhoeae, Neisseria meningitidis, and Neisseria lactamica in chemically defined media and the use of growth requirements for gonococcal typing. $\mathcal{F}$ Infect Dis 1973;128:178-94.

3 Ericsson MM, Sherin JC. Antibiotic sensitivity testing. Report of an international collaborative study. Acta Pathol Microbiol Scand [B] [Suppl] 1971;217.

4 Bygdeman S, Killings I, Danielsson D. Serogrouping and autotyping for epidemiological study of $\beta$-lactamase producing Neisseria gonorrhoeae strains isolated in Sweden. Acta Derm Venereol (Stockh) 1981;6:329-34.

5 Bygdeman S, Danielsson D, Sandström E. Gonococcal W serogroups in Scandinavia. A study with polyclonal and monoclonal antibodies. Acta Pathol Microbiol Scand [B] 1983;91:293-305.
6 Bydeman S, Guillermins EC, Sandström E. Comparison of two different sets of monoclonal antibodies for the serological classification of Neisseria gonorrhoeae. In ington DC: American Society for Microbiology, ington DC

7 Handsfield HH, Sandström EG, Knapp JS, et al. Epidemiology of penicillinase-producing Neisseria gonorrhoeae infections. Analysis by auxotyping and serogrouping. $N$ Engl F Med 1982;306:950-4

8 Sandström E, Danielsson D. Serology of Neisseria gonorrhoeae. Classification by co-agglutination. Acata Pathol Microbiol Scand [B] 1980;88:27-38.

9 Knapp JS, Tam MR, Nowinski RC, Holmes KK, Sandström EG. Serological classification of Neisseria gonorhoeae with use of monoclonal antibodies to gonococcal outer membrane protein I. F Infect Dis 1984;150:44-48.

10 Falk ES, Bjorvatn B, Danielsson D, Kristiansen BE, Melby $\mathrm{K}$, Sorensen $\mathrm{B}$. Restriction endonuclease fingerprinting of chromosomal DNA of Neisseria gonorrhoeae. Acta Pathol Microbiol Scand [B] 1984;92:271-8.

11 Falk ES, Danielsson D, Bjorvatn B, Melby K, Sorensen B, Kristiansen BE. Genomic fingerprinting in the epidemiology of gonorrhoea. Acta Derm Venereol (Stockh) 1985;65:235-9.

12 Falk ES, Danielsson D, Bjorvatn B, et al. Phenotypic and genotypic characterization of penicillinase-producing strains of Neisseria gonorrhoeae. Acta Pathol Microbiol Scand [B] 1985;93:91-7.

13 Falk ES, Bjorvatn B, Kristiansen BE, Sorensen B, Melby K, Danielsson D. Some phenotypic and genotypic characteristics of prevailing gonococcal strains in northern Norway. Genitourin Med 1986;62:9-14.

14 Falk ES, Bygdeman SM, Birkeland NK, Bjorvatn B Kallings I, Sandström EG. Genotypes and phenotypes of $\beta$ lactamase producing strains of Neisseria gonorhoeae from African countries. Genitourin Med 1988;64:226-32.

15 Falk ES, Egglestone ES, Digranes A, Volden G, Bjorvatn B. Genotypic and phenotypic markers in the differentiation of Neisseria gonorrhoeae strains. Acata Pathol Microbiol Immunol Scand [B] 1988;96:109-16.

16 Poh CL, Ocampo JC, Sng EH, Bygdeman SM. Rapid in situ generation of DNA restriction endonuclease patterns for Neisseria gonorrhoeae. I Clin Microbiol 1989; 27:2784-8.

17 O'Callaghan CH. MorrisA, Kirby SM, Shingler AH. Novel method for detection of beta-lactamase by using a method for detection of beta-lactamase by using a chromogenic cephalosporin

18 Birnboim HC, Doly J. A rapid alkaline extraction procedure for screening recombinant plasmid DNA. Nucl Acid Res 1979;7:1513-23.

19 Ish-Horowicz D, Burke JF. Rapid and efficient cosmid cloning. Nucl Acid Res 1981;9:2989-98.

20 Macrina FL, Kopecko DJ, Jones KR, Ayers DJ, McCowen SM. A multiple plasmid-containing Escherichia coli strain: convenient source of size reference plasmid molecules. Plasmid 1978;I:417-20.

21 Sandström E, Lindell P, Harfast B, Blamberg F, Ryden AC, Bygdeman S. Evaluation of a new set of Neisseria gonorhoeae serogroup W-specific monoclonal antibodies for serovar determination. In: Schoolnick GK (ed). The pathogenic Neisseriae. Washington
ety for Microbiology, 1985:26-30.

22 Plikaitis BD, Carbone GM, Edmons P, Mayer LW. Robus estimation of standard curves for protein molecular
entistis weight and linear-duplex DNA base pair number after gel electrophoresis. Ann Biochem 1986;152:346-64.

23 Romsburg MC. Cluster Analysis for Researchers. Belmont, CA: Liftime Learning Publict., 1984

24 SSPX User's Guide. 2nd edition, New York: McGraw-Hill, 1986.

25 Sarafian SK, Knapp JS. Molecular epidemiology of gonorrhoeae. Clin Microbiol Rev 1989;2:S49-S55.

26 BaróT, García A. Penicillinase producing Neisseria gnorrhoeae in a hospital in Barcelona, Spain. Genitourin Med 1987;63:60. 